\title{
Water Relations of Fruit End Cracking in French Prune (Prunus domestica L. cv. French)
}

\author{
Rémy E. Milad ${ }^{1}$ and Kenneth A. Shackel ${ }^{2}$ \\ Department of Pomology, University of California, Davis, CA 956164683 \\ Additional index words. fruit growth, skin mechanical properties, solute distribution, splitting, water stress
}

\begin{abstract}
Irrigation of previously water-stressed French prune trees is known to induce fruit end cracking. The relationships between end cracking, water relations, and mechanical properties of the skin of French prune were studied as a function of irrigation regimes under field conditions. Water stress resulted in the accumulation of solutes in the fruit of nonirrigated trees. A gradient in osmotic potential $\left(\Psi_{\mathrm{s}}\right)$ existed along the vertical axis of fruit from all treatments; $\Psi_{\mathrm{s}}$ was always lower at the stylar than stem end. Irrigation of previously water-stressed trees (irrigateddry treatment) resulted in $\Psi_{\mathrm{s}}$ gradients exceeding those of all other treatments. Moreover, estimated turgor ( $\Psi_{\mathrm{p}}$ ) at the stylar end of the fruit increased 2-fold within 24 hours after irrigation. These changes were accompanied by the onset of fruit end cracking, and neither the well-watered controls nor the continuously droughted fruit exhibited such changes. During the 24 hours following irrigation, the overall $\Psi_{\mathrm{s}}$ of irrigated-dry treatment fruit was diluted by the same amount as the calculated increase in fruit volume. However, during the same period, $\Psi_{\mathrm{s}}$ at the stem end of the fruit showed more dilution than expected, and $\Psi_{s}$ at the stylar end of the fruit concentrated, indicating a redistribution of solutes. There were no differences in skin mechanical properties along the fruit vertical axis and, hence, this could not have accounted for the observed changes in $\Psi_{\mathrm{S}}$ and $\Psi_{\mathrm{p}}$. Thus, when previously stressed French prune trees were irrigated, the overall recovery in water potential $(\Psi)$ and the subsequent movement of solutes to the stylar end of the fruit resulted in apparently excessive turgors in this region and hence the observed pattern of end cracking.
\end{abstract}

Cracking or splitting of fleshy fruit has been observed in a wide variety of species, such as tomatoes (Lycopersicon esculentum Mill.) (Frazier, 1934; Frazier and Bowers, 1947), avocados (Persea americana Mill.) (Haas, 1936), apples (Malus domestica Borkh.) (Goode et al., 1975), and cherries (Prunus avium L.) (Verner and Blodgett, 1931). In the 'French' prune, two types of cracking occur: 1) side cracking, which develops as a fracture on the cheek of the fruit (Mrozek and Burkhardt, 1973), and 2) end cracking, which typically consists of a single split at the apical end of the fruit along the dorsal and ventral sutures. The latter type is most prevalent when a long period of water stress is followed by a midsummer irrigation (Uriu et al., 1962).

In general, cracking may be defined as the physical failure of the fruit skin and is generally thought to result from stresses acting on the skin. In an intact fruit, forces caused by growth or hydration of the fruit flesh will result in proportional stresses acting on the skin (Considine and Brown, 1981). For any given stress, the resulting strain will depend on the structural and mechanical properties of the skin. Therefore, a failure under stress could be due to the internal stresses originating within the fruit and also to the mechanical properties of the skin under stress.

In general, stresses that lead to fruit cracking have been attributed to turgor pressure within the fruit cells, assuming the relation

$$
\Psi=\Psi_{\mathrm{s}}+\Psi_{\mathrm{p}}
$$

where $\Psi, \Psi_{\mathrm{s}}$, and $\Psi_{\mathrm{p}}$ represent water, osmotic, and turgor potentials, respectively (Squire et al., 1981). In an attempt to quantify the factors that lead to cherry cracking, Verner and Blodgett (1931) found a positive correlation between fruit $\Psi_{\mathrm{s}}$

Received for publication 17 Apr. 1992. Accepted for publication 6 May 1992. The cost of publishing this paper was defrayed in part by the payment of page charges. Under postal regulations, this paper therefore must be hereby marked advertisement solely to indicate this fact.

'Graduate Student/Research Assistant.

${ }^{2}$ Assistant Professor/Assistant Pomologist, corresponding author. and cracking after immersion in water. In contrast, Tucker (1934) and Christensen (1972) found that varietal differences in $\Psi_{\text {s }}$ were not correlated with cherry cracking indices obtained using Verner's immersion method. Another study (Andersen and Richardson, 1982) estimated fruit water potential parameters ( $\Psi, \Psi_{\mathrm{s}}$, and $\Psi_{\mathrm{p}}$, using a pressure chamber on fruit pedicels for $\Psi$ and a refractometer for $\Psi_{\mathrm{s}}$ ) of 'Napoleon' cherry trees treated with chemicals known to alter fruit water relations and cracking. In addition, cracking indices of treated fruit were calculated using the immersion method. No correlation was found between $\Psi, \Psi_{\mathrm{s}}$, or $\Psi_{\mathrm{p}}$, and fruit cracking on the day the experiment was performed (harvest day). Finally, Considine and Kriedemann (1972) attempted to estimate the $\Psi_{\mathrm{p}}$ at which grape (Vitis vinifera L.) berries burst. After immersing berries of known $\Psi_{s}$ in a range of osmotica, critical turgor was calculated as the $\Psi_{\mathrm{P}}$ (solution $\Psi_{s}-$ fruit $\Psi_{s}$ ) at which $50 \%$ of the berries split. Cultivars highly susceptible to splitting had $\Psi_{\mathrm{P}}$ values in the range 1.4-2.0 $\mathrm{MPa}$. Moderately susceptible cultivars had an average $\Psi_{\mathrm{p}}$ of $3.1 \mathrm{MPa}$, while the critical turgor of 'Muscat Gordo Blanco', a highly resistant cultivar, was 4.95 MPa.

Several techniques have been used to quantify fruit skin mechanical properties in relation to fruit cracking. In all instances, an artificial source of stress is applied. For example, in the case of rain cracking of cherries (Levin et al., 1959), strips of skin with different moisture contents exhibited different mechanical properties when subjected to a constant rate of strain (i.e., tensile testing). Skins with a higher moisture content had a lower modulus of elasticity (stress/strain), and Levin et al. (1959) hypothesized that skin with a low modulus of elasticity would be associated with an increased possibility of cracking in whole fruit. Lustig and Bernstein (1985) injected water into intact grape berries from cultivars differing in field-cracking susceptibility and determined the increase in stress and strain of the fruit skin. Resistant cultivars exhibited larger strain values for any level of stress than susceptible cultivars. Contrary to Levin et al. (1959), Lustig and Bernstein (1985) suggested that a skin with

Abbreviations: DFB, days after full bloom; $\Psi$, water potential; $\Psi_{\mathrm{P}}$, turgor potential; $\Psi_{s}$, osmotic potential. 
a low modulus of elasticity was able to expand with a very small stress buildup and no cracking.

Studies investigating the relationship between fruit water relations and cracking have generally been performed under laboratory conditions using fruit detached from the plant. Although most studies have been successful in inducing cracking in such detached fruit, the degree of similarity in water relations of detached fruit and fruit attached to plants under field conditions is uncertain. Under field conditions, the stresses developed within the fruit $\left(\Psi_{\mathrm{P}}\right)$ will depend on both fruit $\Psi_{\mathrm{S}}$ and the degree to which fruit $\Psi$ is coupled to plant $\Psi$. In this study, the changes in plant $\Psi$, together with fruit $\Psi_{\mathrm{S}}$ and fruit-skin mechanical properties were studied under field conditions known to induce end cracking in 'French' prune (Uriu et al., 1962). The goal of the following experiments was to determine whether end cracking of prunes was associated with changes in turgor-related stresses within the fruit or changes in fruit-skin mechanical properties.

\section{Materials and Methods}

Plant material and irrigation methods. Seven-year-old 'French' prune trees on Marianna 2624 rootstock located at the Univ. of California Pomology experimental orchards, Davis, were drip irrigated with emitters spaced at 33-cm intervals over the entire orchard floor. The "wet" treatment consisted of several irrigations per day to keep a 10 - to $20-\mathrm{KPa}$ soil tension within the upper $1 \mathrm{~m}$ of soil throughout the growing season. The "dry" plot received no water during the growing season. The "irrigated-dry" plot received no water until 115 days after full bloom (DFB), when sufficient irrigation was applied to wet the soil profile to $1.8 \mathrm{~m}$. A second irrigation was applied at 123 DFB to maintain conditions known to be conducive to fruit end cracking.

Determination of fruit growth and cracking. The diameter of individual tagged fruit was measured perpendicular to the fruit suture (cheek diameter) with a digital hand-held micrometer. Measurements were performed on 6, 12, and 7 fruit in the wet, dry, and irrigated-dry treatments, respectively (unequal numbers due to fruit drop). Cheek diameter was also used to estimate the change in fruit volume during the cracking period by correlating the cheek diameter to the volume of individual fruit, determined using a water displacement method. End cracking was quantified by monitoring tagged branches, and newly formed end cracks were counted in the morning and expressed as a percentage of all monitored fruit $(\mathrm{n} \approx 160$ for each treatment).

Determination of tree and fruit water relations. Leaf total water potential $(\Psi)$ was measured with a pressure chamber (Soil Moisture Equip. Corp., Santa Barbara, Calif.) using exposed leaves that had been covered with an individual plastic bag just before severing the petiole to avoid desiccation (Turner, 1981). Stem $\Psi$ (McCutchan and Shackel, 1992) was determined from leaves that had been individually covered with a black polyethylene/aluminum foil pouch at least $7 \mathrm{~h}$ earlier and had been assumed to be in equilibrium with stem $\Psi$. The osmotic potential $\left(\Psi_{\mathrm{s}}\right)$ at several positions within the fruit was obtained over the growing season from a four-fruit sample per treatment. A cylinder of fruit flesh and skin was removed from each fruit position using a cork borer. Two diametrically opposite cylinders were taken from the stem end of the fruit and two from the stylar end. Individual samples were placed in $1.8-\mathrm{ml}$ plastic vials and immediately frozen in liquid nitrogen. The osmotic potential of juice extracted from samples thawed in a 30C bath was measured using a vapor pressure osmometer (Model 5500, Wescor, Logan, Utah) calibrated with $\mathrm{NaCl}$ standards. Esti- mation of fruit $\Psi_{\mathrm{P}}$, at predawn was based on the assumption that predawn fruit $\Psi$ was equivalent to predawn stem $\Psi$, since $\Psi$ gradients should be minimal at this time. $\Psi_{\mathrm{p}}$ at different fruit positions (fruit stem end vs. stylar end) was calculated by subtracting $\Psi_{S}$ obtained for that particular position from predawn stem $\Psi$ (Eq. [1]).

Fruit hydration experiments. These experiments were performed to determine the effects of fruit hydration on the $\Psi_{\mathrm{s}}$ at different positions (stem end vs. stylar end) within the fruit. Leaves on one or two adjacent fruiting branches per treatment were individually covered as for stem $\Psi$ in the morning, and in the afternoon the branches were severed, enclosed in black polyethylene bags, and transported to the laboratory within $15 \mathrm{~min}$. A flexible plastic hose was used to supply deionized water to the cut end of the branch. These hydration experiments were performed on two occasions during the growing season on branches obtained from the wet and dry treatments. Stem $\Psi$ and fruit $\Psi_{\mathrm{s}}$ were determined using the same methods as described above.

Determination of skin mechanical properties. Skin extensibility and creep were determined on fruit skin strips taken from different positions on a fruit, using a uniaxial creep apparatus similar to the one used by Matthews et al. (1987). To reduce frictional forces, pulleys were replaced with a lever beam. Fruit samples were randomly picked from the wet and dry plots, put in sealable plastic bags, and frozen at $-70 \mathrm{C}$. Before the measurements, bags were transferred to $-30 \mathrm{C}$, and the fruit were thawed, one at a time, just before skin isolation. Two parallel slits, $5 \mathrm{~mm}$ apart, were made along the longitudinal fruit axis with fixed razor blades. One strip of skin $(5 \times 20 \mathrm{~mm}$ width/ length) was taken from the stem end, and a similar strip was taken from the stylar end. Each strip was taken midway between the fruit equator and the respective pole. The samples were then immersed in mineral oil to prevent desiccation and clamped into position. The initial length of fruit skin between the clamps was $10 \mathrm{~mm}$. After clamping, a small load (1 g) was applied to the test strip for 2 min to establish a stable baseline (Richmond et al., 1980). A 15-g load was then added, resulting in an instantaneous extension followed by a time-dependent elongation (creep). After $7 \mathrm{~min}$, the 15-g load was removed and the test strip allowed to recover for $7 \mathrm{~min}$. After load removal, an instantaneous contraction occurred followed by a time-dependent contraction. Plastic deformation $\left(\mathrm{D}_{\mathrm{P}}\right)$ was calculated as the difference between the final and initial strip lengths. The elastic deformation $\left(\mathrm{D}_{\mathrm{e}}\right)$ was determined as the fully recoverable component of total deformation $\left(D_{t}\right)$. Creep was calculated as the percent extension between 1 and $7 \mathrm{~min}$ after applying the full load. Also, $D_{P}, D_{e}$, and $D_{t}$ were expressed as percent deformation of initial test strip length $(10 \mathrm{~mm})$.

\section{Results}

Fruit growth. As is typical for fruit showing a double sigmoid growth pattern, tagged prune fruit exhibited an increase in fruit growth at the start of fruit growth stage III (Lilleland, 1933), around 75 DFB in wet and dry treatments (Fig. 1). The diameter of fruit in the irrigated-dry treatment showed a marked increase following irrigation at $115 \mathrm{DFB}$ and an additional increase 5 days later.

Treelfruit water relations and cracking. Predawn and midday $\Psi$ showed similar treatment effects during the period of 113131 DFB (Fig. 2). In the wet treatment, there was little change in $\Psi$, whereas there was a gradual decline in $\Psi$ in the dry treatment. After irrigation (115 DFB), both predawn and mid- 


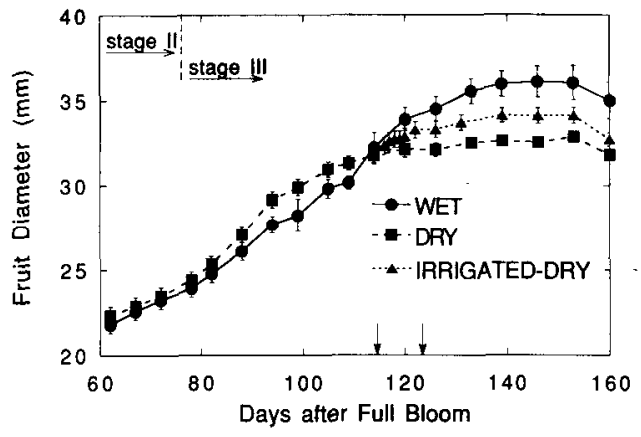

Fig. 1. Average diameter of tagged fruit from the wet, dry, and irrigated-dry treatments. Vertical bars are \pm 1 SE. Arrows indicate irrigation dates for the irrigated-dry plots.

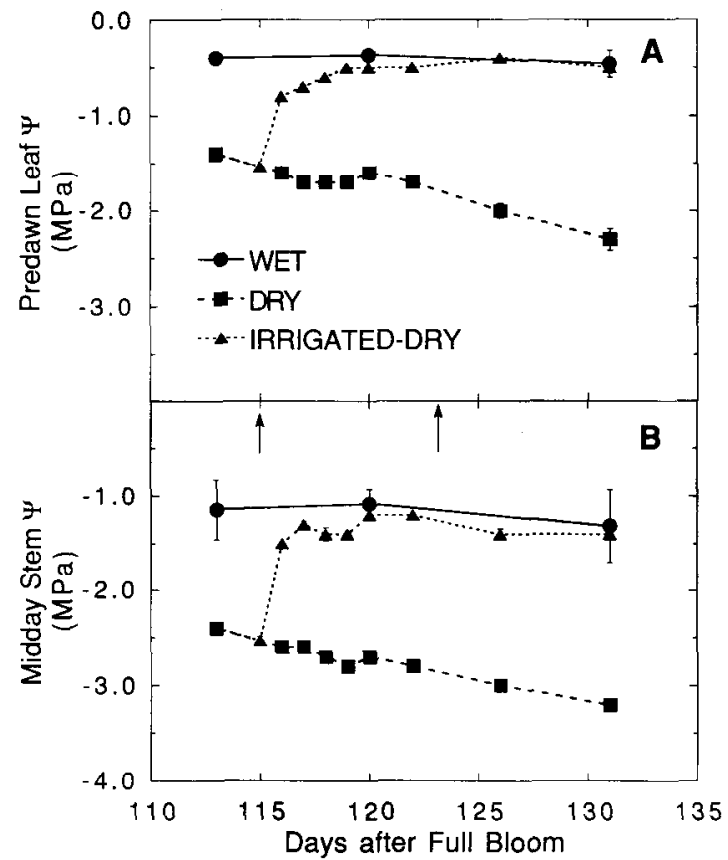

Fig. 2. (A) Leaf water potentials $(\Psi)$ at predawn and (B) midday stem water potentials in the wet, dry, and irrigated-dry plots. Vertical bars are $\pm 1 \mathrm{SE}$. Bars smaller than symbols are hidden. Arrows indicate irrigation dates for the irrigated-dry plot.

day $\Psi$ in the irrigated-dry treatment recovered to the level of the wet treatment. $\Psi_{s}$ was similar at the stem and stylar end of fruit in both wet and dry treatments until $\approx 90$ DFB (Fig. 3A). After this time, differences in $\Psi_{\mathrm{s}}$ between the stem and stylar ends $\left(\Delta \Psi_{s}\right.$, Fig. 3B) increased in both treatments but to a larger extent in the wet treatment (in all cases, stylar $\Psi_{s}$ was lower than stem $\Psi_{\mathrm{s}}$ ). After irrigation, $\Delta \Psi_{\mathrm{s}}$ in the irrigated-dry treatment was markedly higher than in either the wet or dry treatment (Fig. 3B). Within $24 \mathrm{~h}$ after irrigation in the irrigated-dry treatment, whole-fruit $\Psi_{s}$ exhibited an increase (dilution) that was essentially identical to the increase in fruit volume that occurred during the same period (Table 1). During this period, $\Psi_{\mathrm{S}}$ at the fruit stem end exhibited a much larger increase than that exhibited in the whole fruit, whereas fruit stylar end $\Psi_{\mathrm{s}}$ decreased (Table 1).

The rapid increase in plant $\mathrm{Y}$ (Fig. 2A), together with the decrease in $\Psi_{s}$ at the stylar end of the fruit in the irrigated-dry treatment (Fig. 3A), resulted in a substantial increase in the estimated predawn $\Psi_{\mathrm{p}}$ at the fruit stylar end (Fig. 4A), coincident with the occurrence of fruit end cracks (Fig. 4B). In the

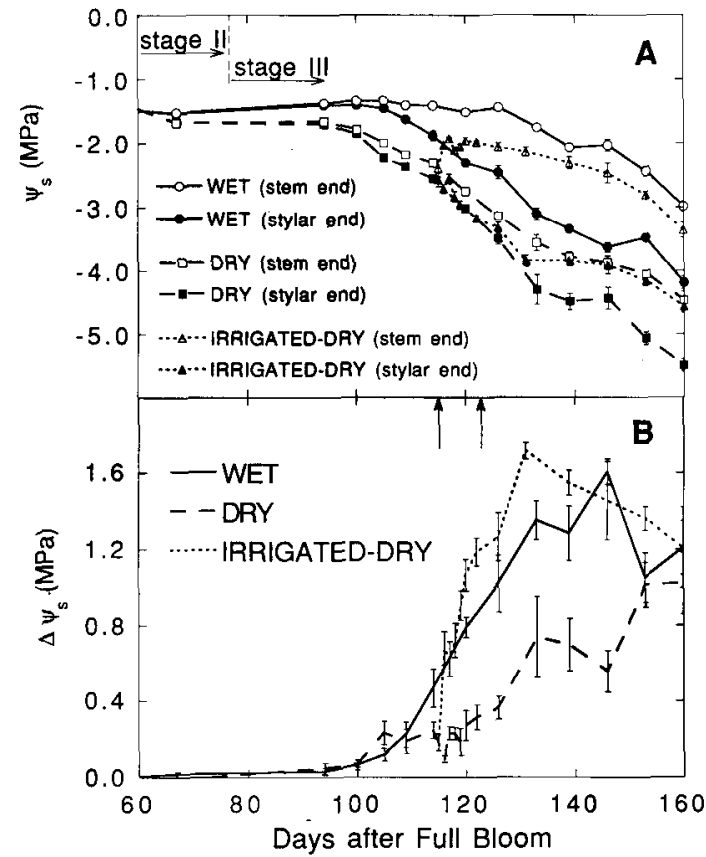

Fig. 3. (A) Seasonal changes in osmotic potential $\left(\Psi_{\mathrm{s}}\right)$ for the stem end and stylar end positions of fruit in the wet, dry, and irrigateddry treatments. (B) Differences in osmotic potential between the stem end position and stylar end position $\left(\Delta \Psi_{\mathrm{s}}=\right.$ Stem $\Psi_{\mathrm{s}}-$ Stylar $\Psi_{\mathrm{s}}$ ). Vertical bars are \pm 1 SE. Bars smaller than symbols are hidden. Arrows indicate irrigation dates for the irrigated-dry treatment.

Table 1. Fruit osmotic potential values $\left(\Psi_{\mathrm{s}}\right)$ before $(115 \mathrm{DFB})$ and after (116 DFB) irrigation for the irrigated-dry treatment.

\begin{tabular}{lccr}
\hline \hline Part of fruit & $\begin{array}{c}115 \mathrm{DFB}(6 \text { July) } \\
\text { (MPa) }\end{array}$ & $\begin{array}{r}\text { DFB(7 July) } \\
\text { (MPa) }\end{array}$ & $\begin{array}{r}\text { Change } \\
(\%)\end{array}$ \\
\hline Whole & -2.48 & -2.37 & 4.4 \\
Stem end & -2.39 & -2.03 & 14.4 \\
Stylar end & -2.57 & -2.71 & -5.5 \\
Calculated fruit vol change & & & 4.3 \\
\hline
\end{tabular}

$24 \mathrm{~h}$ following irrigation, there was a large ( $0.9 \mathrm{MPa})$ and highly significant (Student's $t$ test, $P=0.001$ ) increase in $\Psi_{\mathrm{p}}$ at the stylar end of irrigated-dry treatment fruit compared with a relatively constant $\Psi_{\mathrm{p}}$ in the stylar end of the dry-treatment fruit (Fig. 4A). During the same period, a smaller (0.4 MPa) and nonsignificant (Student's $t$ test, $P=0.345$ ) increase in $\Psi_{\mathrm{P}}$, occurred at the stem end of irrigated-dry treatment fruit, compared with a more variable $\Psi_{\mathrm{p}}$ in the stem end of the dry treatment fruit (data not shown). The rate of change in fruit stylar end $\Psi_{\mathrm{p}}$ exhibited a double-peak pattern with high values (rapid increases) occurring on the morning following irrigation and 2 days later (Fig. 4B). The appearance of new end cracks also exhibited a double-peak pattern, with the first peak occurring 2 days after irrigation, followed by a smaller peak 3 days later (Fig. 4B). During the period of 115-131 DFB, a total of $28 \%$ of the fruit in the irrigated-dry treatment exhibited end cracks (Fig. 4B), whereas only 3\% of the fruit in the dry treatment (at $120 \mathrm{DFB}$ ) and no fruit in the wet treatment exhibited end cracks (data not shown).

Hydration experiments. Under laboratory conditions, the stem $\Psi$ of hydrating branches increased from the midday values exhibited under field conditions (Fig. 2) to about $-0.1 \mathrm{MPa}$ within 20 min of applying water to the stem cut end (data not shown). By $24 \mathrm{~h}$, the fruit on the branches had increased in both volume 


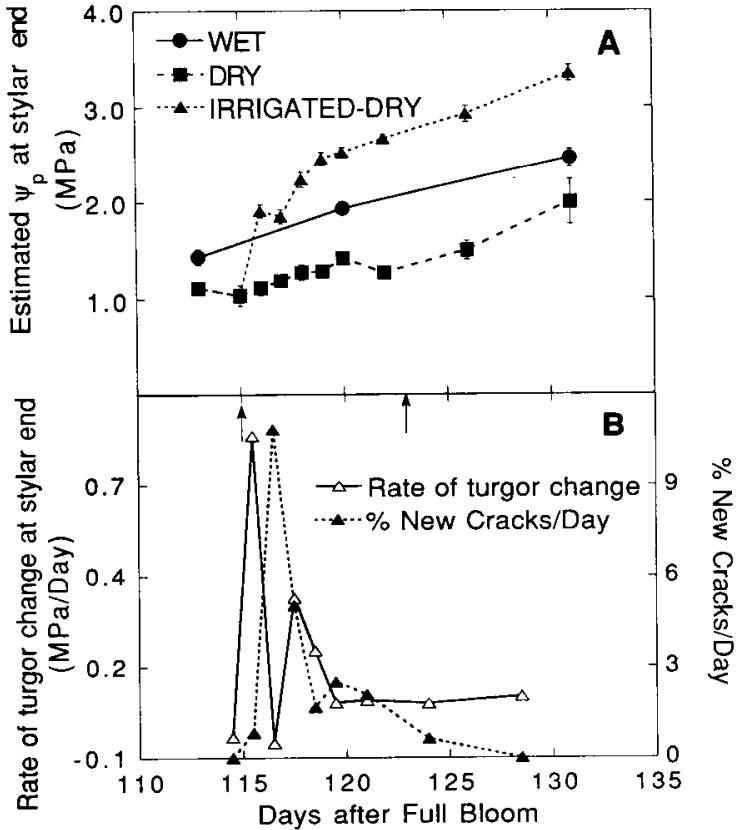

Fig. 4. (A) Estimated predawn turgor pressure $\left(\Psi_{\mathrm{P}}\right)$ at the fruit stylar end. (B) Rate of $\Psi_{\mathrm{P}}$ change at the stylar end of fruit from the irrigated-dry treatment and percent new end cracks observed during this period. Vertical bars are $\pm 1 \mathrm{SE}$. Bars smaller than symbols are hidden. Arrows indicate irrigation dates for the irrigated-dry treatment.

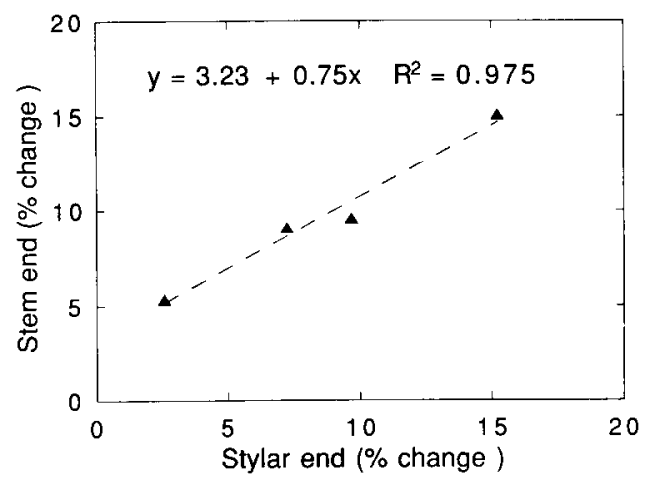

Fig. 5. Correlation between percent changes in osmotic potential at the fruit stylar end and percent changes in osmotic potential at the fruit stem end for all hydration experiments (wet and dry treatments at 98 and $102 \mathrm{DFB}, 24-\mathrm{h}$ hydration period).

and $\Psi_{s}$, with fruit in the dry treatment showing larger increases than those in the wet treatment. In all cases, however, the relative change in fruit $\Psi_{\mathrm{s}}$ was roughly equivalent at the stem and stylar ends (Fig. 5), indicating a uniform hydration across the fruit. The differential response of stylar end concentration and stem end dilution that was observed under field conditions upon irrigation (Fig. 3A) was not exhibited in the laboratory, nor was fruit end cracking.

Skin mechanical properties. Skin $\mathrm{D}_{\mathrm{t}}$ and $\mathrm{D}_{\mathrm{p}}$ did not change during the period $67-146 \mathrm{DFB}$ in the wet or the dry treatment and were similar for both treatments (data not shown). Conversely, skin $\mathrm{D}_{\mathrm{e}}$ (Fig. 6) and creep (data not shown) in fruit of the dry treatment were generally lower than those of fruit in the wet treatment after 110 DFB. Creep of skin from dry-treatment fruit was at its lowest during the period 113-131 DFB (data not shown). Stem and stylar end skin mechanical properties did not

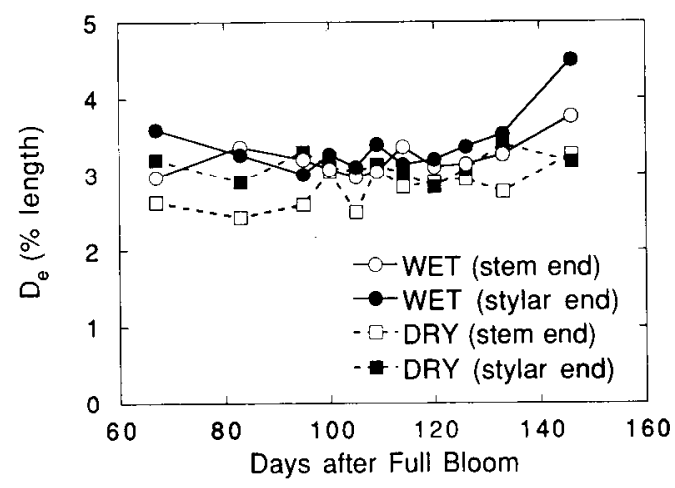

Fig. 6. Seasonal pattern of $\mathrm{D}_{\mathrm{e}}$ (elastic or recoverable deformation) for the stem end and stylar end fruit skin from the dry and wet treatments.

show any consistent differences from 67 to 146 DFB (data shown for $\mathrm{D}_{\mathrm{e}}$, Fig. 6).

\section{Discussion}

The $\Psi_{s}$ of fruit in the dry treatment was always lower than the $\Psi_{\mathrm{s}}$ of fruit in the wet treatment, and some of this difference remained after irrigation in the irrigated-dry treatment (Fig. 3A). Similarly, under laboratory conditions, the $\Psi_{\mathrm{s}}$ of hydrated fruit of the dry treatment was 0.3 to $0.4 \mathrm{MPa}$ lower than the $\Psi_{\mathrm{s}}$ of hydrated fruit of the wet treatment (data not shown). These results indicate an accumulation of solutes in fruit as a result of withholding irrigation. One consequence of this accumulation is that low fruit $\Psi_{\mathrm{S}}$ would result in high fruit $\Psi_{\mathrm{p}}$ if the increase in fruit $\Psi$ is similar to the increase that occurs in plant $\Psi$ upon reirrigation. In this study we used stem $\Psi$ as an estimate of fruit $\Psi$ under predawn conditions. After irrigation of previously stressed prune trees, we found a marked increase in $\Psi_{\mathrm{p}}$ at the stylar end of the fruit, together with fruit end cracking. These results indicate that both changes in fruit $\Psi$ and fruit $\Psi_{\mathrm{S}}$ influence $\Psi_{\mathrm{P}}$ and may be responsible for the occurrence and pattern of end cracking in French prune. Consequently, stresses experienced by the fruit might determine the timing and location of end cracks in French prune.

In addition to the long-term overall decrease in fruit $\Psi_{s}$, a large gradient in $\Psi_{s}$ across the fruit $\left(\Delta \Psi_{s}\right)$ was also found in all treatments, particularly at the end of the season ( $\Psi_{\mathrm{s}}$ always lower at the stylar end). A similar $\Psi_{\text {s }}$ gradient, although reversed, was reported in navel orange (Citrus sinensis Osb.) fruit (Kaufmann, 1970). Also, concentrations of glucose and fructose in the outer flesh of grape berries were found to increase from the pedicel to the stylar end (Coombe, 1987). In our study, $\Delta \Psi_{\mathrm{s}}$ in the irrigated-dry treatment exhibited a 3-fold increase within $24 \mathrm{~h}$ after irrigation, exceeding that of the other treatments (Fig. 3B). At the stem end of the fruit, there was a $\Psi{ }_{s}$ increase (dilution) of $14.9 \%$, whereas at the stylar end, $\Psi{ }_{s}$ decreased (concentrated) $5.5 \%$ (Table 1). The mean change in $\Psi_{\text {s }}$ for the whole fruit was an increase of $4.4 \%$, which corresponded closely to the dilution expected based on the observed volume change. Hence, the large $\Delta \Psi$ s apparently developed as a result of solute redistribution. The change in fruit stylar end $\Psi_{s}$ in conjunction with the rapid recovery of predawn $\Psi$ in the plant (and presumably the fruit) resulted in an overnight 2 -fold increase in the estimated $\Psi_{\mathrm{P}}$ at the stylar end of the fruit (Fig. 4A), coinciding with the occurrence of cracks at this position. Although the rates of $\Psi_{\mathrm{P}}$ change and end cracking are not identical, a two-peak pattern is apparent in both characteristics (Fig. 4B). The 1- to 
2-day delay between the appearance of these changes could have resulted from our inability to accurately determine the initial stages of crack formation until after crack widening by further fruit growth.

Other factors may also be involved in prune end cracking and could have influenced fruit cell $\Psi_{\mathrm{p}}$. First, the presence of solutes in the apoplastic space (Cosgrove and Cleland, 1983) would have a profound effect on the $\Psi_{\mathrm{P}}$ of fruit cells, with any apoplastic $\Psi_{\mathrm{s}}$ values proportionally reducing cell $\Psi_{\mathrm{p}}$. Direct measurement of cell $\Psi_{\mathrm{S}}$ and $\Psi_{\mathrm{p}}$ (Shackel, 1987) will be required to determine the impact of apoplastic solutes on fruit cell $\Psi_{\mathrm{p}}$, although the substantial redistribution of solutes toward the stylar end of the fruit strongly suggests that the differential $\Psi_{\mathrm{P}}$ buildup along the fruit axis could be considerable. Second, lower skin $\mathrm{D}_{\mathrm{e}}$ and creep values in the stressed fruit reflect a stiffening of the skin during the period of 113-131 DFB. Skin stiffening might be due to an altered geometry of the dermal cell walls, which tend to be thicker and stiffer in plant tissues subjected to water stress (Lawlor and Leach, 1985). Although this skin property might not influence the extent of pressure buildup within the fruit after hydration, it might, however, result in a larger rate of pressure and stress increase in the whole fruit. However, the mechanical properties of the skin at the stem and stylar ends were similar, suggesting a homogeneity along the fruit vertical axis (data shown for $\mathrm{D}_{\mathrm{e}}$ only; Fig. 6). Consequently, the larger stress rates at the stylar end could not have been due to spatial differences in skin mechanical properties.

Our observations suggest that solute accumulation, while potentially beneficial for the maintenance of cell turgor at low fruit $\Psi$, could result in high and possibly excessive fruit cell $\Psi_{\mathrm{p}}$ when a rapid plant and fruit $\Psi$ recovery occurs, as is known to be associated with end cracking of prunes (Uriu, 1962). In addition to the overall $\Psi$ recovery after irrigation, there is also evidence of solute movement within the fruit. Within the fruit, cells near the stem end may be the first to be influenced by the recovery in plant $\Psi$. A subsequent movement of solutes to the distal part of the fruit (stylar end), together with overall higher fruit $\Psi$, may cause excessive turgors to build up, causing the observed end-cracks. The transport mechanisms (apoplastic, symplastic, or phloem mediated) underlying such a phenomenon remain to be elucidated.

\section{Literature Cited}

Andersen, P.C. and D.G. Richardson. 1982. A rapid method to estimate fruit water status with special reference to rain cracking of sweet cherries. J. Amer. Soc. Hort. Sci. 107:441-444.

Christensen, J.V. 1972. Cracking in cherries. IV. Physiological studies of the mechanism of cracking. Acta Agr. Scandinavica 22:1.53-162.

Considine, J.A. and K.C. Brown. 1981. Physical aspects of fruit growth: Theoretical analysis of distribution of surface growth forces in fruit in relation to cracking and splitting. Plant Physiol. 68:371-376.

Considine, J.A. and P.E. Kriedemann. 1972. Fruit splitting in grapes:
Determination of the critical turgor pressure. Austral. J. Agr. Res. 23:17-24.

Coombe, B.G. 1987. Distribution of solutes within the developing grape berry in relation to its morphology. Amer. J. Enol. Viticult. 38:120-127.

Cosgrove, D.J. and R.E. Cleland. 1983. Solutes in the free space of growing stem tissues. Plant Physiol. 72:326-331.

Frazier, W.A. 1934. A study of some factors associated with the occurrence of cracks in the tomato fruit. Proc. Amer. Soc. Hort. Sci. 32:519-523.

Frazier, W.A. and J.L. Bowers. 1947. A final report on studies of tomato fruit cracking in Maryland. Proc. Amer. Soc. Hort. Sci. 49:241-255.

Goode, J.E., M.M. Fuller, and K.J. Hyrycz. 1975. Skin-cracking of Cox's Orange Pippin apples in relation to water stress. J. Hort. Sci. 50:265-269.

Haas, A.R.C. 1936. Growth and water relations of the avocado fruit. Plant Physiol. 11:383-400.

Kaufmann, M.R. 1970. Water potential components in growing citrus fruits. Plant Physiol. 46:145-149.

Lawlor, D.W. and J.E. Leach. 1985. Leaf growth and water deficits: biochemistry in relation to biophysics, p. 267-294. In: N.R. Baker, W.J. Davies, and C.K. Ong (eds.). Control of leaf growth. Soc. Expt. Biol. Seminar Ser. 27, Cambridge, Cambridge Univ. Press.

Levin, J.H., C.W. Hall, and A.P. Deshmukh. 1959. Physical treatment and cracking of sweet cherries. Mich. State Univ. Agr. Expt. Sta. Quart. Bul. 42:133-141.

Lilleland, 0. 1933. Growth study of the plum fruit. I. The growth and changes in chemical composition of the Climax plum. Proc. Amer. Soc. HortSci. 30:203-208.

Lustig, I. and Z. Bernstein. 1985. Determination of the mechanical properties of the grape berry skin by hydraulic measurements. Scientia Hort. 25:279-285.

Matthews, M.A., G. Cheng, and S.A. Weinbaum. 1987. Changes in water potential and dermal extensibility during grape berry development. J. Amer. Soc. Hort. Sci. 112:314-319.

McCutchan, H. and K.A. Shackel. 1992. Stem water potential as a sensitive indicator of water stress in prune trees (Prunus domestica L. cv. French). J. Amer. Soc. Hort. Sci. 117:607-611.

Mrozek, R.F. and T.H. Burkhardt. 1973. Factors causing prune side cracking. Trans. Amer. Soc. Agr. Eng. 16:686-692, 695.

Richmond, P.A., J.-P. Métraux, and L. Taiz. 1980. Cell expansion patterns and directionality of wall mechanical properties in Nitella. Plant Physiol. 65:211-217.

Shackel, K.A. 1987. Direct measurement of turgor and osmotic potential in individual epidermal cells. Plant Physiol. 83:719-722.

Squire, G.R., C.R. Black, and P.J. Gregory. 1981. Physical measurements in crop physiology II. Water relations. Expt. Agr. 17:225242.

Tucker, L.R. 1934. A varietal study of the susceptibility of sweet cherries to cracking. Univ. of Idaho Agr. Expt. Sta. Bul. 211:1-15.

Turner, N.C. 1981. Techniques and experimental approaches for the measurement of plant water status. Plant \& Soil 58:339-366.

Uriu, K., C.J. Hansen, and J.J. Smith. 1962. The cracking of prunes in relation to irrigation. Proc. Amer. Soc. Hort. Sci. 80:211-219.

Verner, L. and E.C. Blodgett. 1931. Physiological studies of the cracking of sweet cherries. Univ. of Idaho Agr. Expt. Sta. Bul. 184:115 . 